\title{
MCMINDFULNESS: HOW MINDFULNESS BECAME THE NEW CAPITALIST SPIRITUALITY, BY RONALD PURSER (REPEATER BOOKS, 2019)
}

\author{
MAJD JAMAL HAMMOUDEH ${ }^{l}$
}

Roland Purser is a Professor of Management based in San Francisco. According to his personal profile on the College of Business of San Francisco State University's website, his article "Beyond McMindfulness" led to a long series of publications about issues related to introducing mindfulness into secular contexts. He contributed to the writing of two books, the Handbook of Mindfulness: Culture, Context and Social Engagement and the Handbook of Ethical Foundations of Mindfulness. For later reference, it is worthwhile noting that he is an ordained Zen Dharma Teacher in the Korean Zen Taego order of Buddhism.

The McMindfulness book, with its thirteen chapters and a conclusion, aims at providing a critique of mindfulness as a discourse and a practice and challenges its contemporary usage and its commodification. It questions the credibility of contemporary mindfulness practice, focusing mainly on how it has turned into a movement for privatizing mindfulness and making it a personal issue, whereby each individual is made responsible for applying it to all attributes of life, combined with how capitalist organizations and ventures are using the concept to influence their employees to become more productive while increasing their own profit.

From the first page of the book, Purser begins by challenging the concept of mindfulness and its practitioners who claim that paying attention to the present moment with no judgement can reduce human suffering and transform the world while igniting a global renaissance - from his point of view, it solely represents a coping mechanism being offered as a product - and not a "well packaged" one. Purser perceives that personal stress has a societal cause and effect, thus when talking about suffering this should include the concept of the collective

1 Majd Jamal Hammoudeh, PhD Candidate, Doctoral School of Sociology, Eötvös Loránd University (ELTE), Budapest, email: majdjh@caesar.elte.hu 
so people are not only focused on themselves when they think of mindfulness. The causes of social distress, injustice, inequity, and environmental devastation are the problems Purser seeks to discuss, which, in his opinion, need to be concentrated on - not the ways to reduce the individual suffering that the former phenomena cause on the intrapersonal level, which mindfulness, according to Purser, is all about. Purser points out on more than one occasion in the book that mindfulness is neither a Buddhist practice, nor a method of corporate social responsibility - in contrast to what corporations may claim.

The term "Neoliberal Mindfulness" is introduced in the book in relation to Purser's discussion of several of the psychological, sociological, and behavioral characteristics of mindfulness: namely, to describe how it became neoliberalized to meet the needs of capitalists by individualizing social problems and ignoring the collective. The definition of neoliberalism by Pierre Bourdieu (a French sociologist and public intellectual known for his work on the dynamics of power in society and the conceptualization of social capital) is used as "the most straightforward definition of neoliberalism," which is as follows: "A program for destroying collective structures which may impede the pure market logic." Purser also reflects on Michel Foucault's (a French philosopher and historian of the twentieth century) theory of governmentality concerning how individuals conduct themselves. In Foucault's description, there are two different modes of power ("techniques of domination" and "techniques of the self"), both of which may be considered instruments, as Purser puts it, "for the formation of selfhood as a neoliberal subject." The new forms of institutionalism tolerate mindfulness due to its depoliticized nature: individuals now bear full responsibility for their happiness and well-being, leading to a neoliberal mindfulness which, according to Purser, suggests that "the source of people's problems is found in their heads."

Another concept - the "mood economy" - is addressed in the book, with a quote from Jennifer Silva (an Assistant Professor of Sociology at Bucknell University) who describes that latter as meaning that: "individuals [are] solely responsible for their emotional fates." Purser goes on to describe mindfulness combined with the "science of happiness" (similar to positive psychology) as a "package" which is actually being sold "as a technique for personal life-hacking optimization, disembedding individuals from social worlds."

Alongside the theories Purser uses to criticize the contemporary uses of mindfulness, he clarifies that mindfulness is not "cruel" in itself; its cruelty derives from being "fetishized and attached to inflated promises" when it is communicated as a means of transformation and a life-changing technique. Quoting from the second chapter: "This is how neoliberal mindfulness promotes an individualistic vision of human flourishing, enticing us to accept things as they are, mindfully enduring the ravages of capitalism." 
John Kabat-Zinn, founder of the Mindfulness Based Stress Reduction (MBSR) program, and his ideology are the subject matter of chapters three, four, and five. Purser argues how mindfulness is being "sold" in the modern world to scientists and thinkers, emphasizing that it "comes from Buddhism" but has become "decontextualized" to better fit today's world and psychology. Purser affirms that Kabat-Zinn intends to rebrand the entire concept of mindfulness, eliminating its religious heritage, and focusing on the scientific side. A number of quotes are used to demonstrate inconsistencies in Kabat-Zinn's approach - for example, a quote from Kabat-Zinn: "[mindfulness was] never meant to exploit, fragment or decontextualized the dharma, but rather recontextualize it." To Purser, Kabat-Zinn's intentions with mindfulness are to start a new lineage. Not only does the writer challenge the medicalization of mindfulness, but also how it has become privatized - the fact that each individual is responsible for their own mental well-being. A quote from the book: "mindfulness targets individuals and seems insensitive to social, political, and economic dimensions of suffering," making individuals, according to Purser, more self-centered and also more accepting of change and challenges, as he clearly states: "It seems to be of no importance whether one's worldview or choices are dysfunctional, because mindfulness allows one to reduce unwanted symptoms - stress, depression and anxiety - even if one's way of life is out of balance with reality." From Purser's perspective, the privatized spirituality of the mindfulness movement disregards collective happiness and communal well-being.

The author has conducted intensive research and includes over 20 pages of references (books, journal articles, conference proceedings, and online articles) to support and defend his arguments. The concentration on Kabat-Zinn and his ideologies, books, quotes, conference speeches, and other sources is considered important when dealing with mindfulness, as the latter is one of the founders of the modern discourse and has conducted intense scientific research on the issue, which many scientists from different sectors follow, although Purser has contempt for Kabat-Zinn's work.

Furthermore, Purser recognizes the double-faced characteristic of "mindfulness promoters," whose first claim that "mindfulness is science" attempts to convince people thus, while in other arguments they try to show that mindfulness "has Buddhist origins," making it look deep. The writer also criticizes how people have been using mindfulness to serve their own goals - whether to promote success or happiness, productivity at the workplace, wealth, or other side effects of mindfulness - dissimilarly to the objectives of the Dharma (defined in the book as "a collective term for the Buddha's teachings"), and Buddhist meditation, which is better aligned with promoting collective endeavors and communal well-being than individualization. 
Purser details his experience with mindfulness and MBSR programs; he clearly rejected the concept throughout his own journey. While he witnessed people healing, he felt that this was a mistake, and did not feel good himself, thus he questions whether "this mindful revolution was just about coping and fine-tuning our brains so that we can dutifully perform our roles more efficiently - becoming better adjusted cogs in the capitalist machinery?"

Moving to the critical research related to mindfulness, Purser reviewed several research projects and meta-analytical studies of mindfulness and extracted the relevant results. One paper published in Scientific Reports in 2018 that is entitled "The limited prosocial effects of meditation: A systematic review and meta-analysis" concluded that meditation interventions increased the levels of compassion in published studies which had meditation teachers as coauthors and employed passive control groups, not active ones. The same paper claimed that $61 \%$ of studies approving of mindfulness were methodologically weak. Purser offers another point regarding the trustworthiness of measuring mindfulness: "to date, there are at least nine different psychometric questionnaires, all of which define and measure mindfulness differently" - for the author, this raises concerns about reliability, a notable one being the use of self-reported questionnaires, which could cause bias.

The impact on employees and the act of incorporating mindfulness into corporations has a place in the discussion. Purser describes the "Search Inside Yourself" training program at Google and other training programs that have been developed in big multinational corporations. Adopting practices such as mindfulness in corporations to have a "therapeutic focus on individual wellbeing" may disguise the actual reason for the practice: manipulating and controlling employees. Ruminating that the main causes of stress for employees are not taken into consideration (such as a "lack of health insurance, the constant threat of lay-offs, lack of discretion and autonomy in decision-making, long working hours, low levels of organizational justice, and unrealistic demands") Purse claims that no mindfulness program is actually neutral.

In the latter chapters of the book, Purser sheds light on some mindfulness coaches or 'gurus' that have gone to the extreme to deliver the concept of mindfulness to the public, in addition to asking a high price for it (a fee of $\$ 12,000$ per day for a corporate mindfulness training event was the answer of Dawa Darchin Philips when asked in a conference about his consultation fees, which did not sound not appropriate compared to the communicated objectives and purposes of mindfulness). Purser also describes events which took place in Davos (at the annual meeting of the World Economic Forum [WEF]), including speeches which were delivered on the subject of mindfulness, and related arguments that were made. He comments on and criticizes the 
presented research and "proof," coming up with the conclusion that "[c]orporate mindfulness programs perpetuate the myth that individuals are simply "free to choose' between stress and misery or wellness and happiness." Not only is the founder of the Search Inside Yourself program, Chade-Meng Tan, known as the Google's Jolly Good Fellow, mentioned in the book, but so are most advocates of mindfulness and corporations that implement such training: "Jon KabatZinn, Jack Kornfield, Sharon Salzberg, Joan Halifax, Eckhart Tolle, Anderson Cooper, Arianna Huffington, Goldie Hawn and the mindful Congressman Tim Ryan, to name just a few. Corporate sponsors have included Google, Facebook, Yahoo, and MailChimp."

Throughout the book, Purser focuses on criticizing how mindfulness is being privatized and oriented towards creating benefits for corporate entities: by the end of the book, he further disapproves of mindfulness being introduced in schools and the military, even if it may support the wellbeing of traumatized soldiers after returning from a war zone. He does not overlook the political side of mindfulness - see the integration of mindfulness into the UK Parliament in the form of the Mindfulness All-Party Parliamentary Group (MAPPG), established in 2014 in the UK to lead a nine-month study about the matter.

In the final chapters, Purser refers to himself as a Buddhist, which may suggest some bias in the research and book. He includes some comments about how mindfulness neglects Buddhism, even though the basis of mindfulness and its practices come from Buddhism. His critiques are based on some evidence; nevertheless, conflicts of personal interest and his own bias may still be present.

"McMindfulness" helps the reader to understand other perspectives about contemporary mindfulness, and includes reference to a number of research papers and studies in its construction of a comprehensive argument. On the other hand, the topic has been subjectivized, the criticism may involve bias, and, to a certain degree, some statements may be offensive to some readers - the overall tone makes it difficult to comprehend the book in a scientific manner. While Purser proposes that unless the causes of social suffering are examined "along with collective experiences of cultural trauma, systematic racism, and other form of marginalization and displacement that cannot be reduced to psychological maladies" the mindfulness revolution will escalate the problems it is claimed to solve, the book fails to suggest alternatives to those that are rejected with reference to objective and scientific methods - rather, it may offend the mindfulness movement and its proponents.

The book will interest readers who seek further understanding about contemporary mindfulness and those who work on critiquing mindfulness mainly readers of business ethics, psychology, Buddhist studies, social sciences, and organizational sociology. 
